\title{
LA CIUDAD IDEAL DE JACQUES DEMY. REFLEJOS DE NANTES EN OTRAS CIUDADES PORTUARIAS
}

Data recepción: 2013/06/16

Data aceptación: 2013/10/03

Contacto autora: barbarasantos1981@hotmail.com
Bárbara Santos Mato

Universidade de Santiago de Compostela

\section{RESUMEN}

Dentro de la Nouvelle Vague, el cineasta Jacques Demy es una figura singular e innovadora. Su filmografía está profundamente ligada a Nantes. Un amor por esta ciudad que se observa en cada uno de sus trabajos. Aunque solamente filmó en dos ocasiones esta ciudad (Lola y Una habitación en la ciudad), los ecos de Nantes los ha traspasado a las demás ciudades en las que se inscribe el resto de su obra. Gracias a su personalísima visión de un universo "en-chante" nos presenta su ciudad ideal, siempre a partir de su deseo de descubrir un cosmos repleto de color y música homenajeando a los grandes musicales de Hollywood. La ciudad como un lugar de ensueño repleto de colores que complementan el desarrollo de la historia y los caracteres de los personajes; un elemento indispensable y característico de la filmografía del autor que se convierte en un personaje más.

Palabras clave: Jacques Demy, ciudad ideal, Nantes, puertos, musical.

\section{ABSTRACT}

Although associated with the Nouvelle Vague, the film-maker Jacques Demy is a unique and innovative personality. His filmography is deeply connected to Nantes. The love for this city IS present in all of his works. Despite Jacques Demy only shot two films in this city (Lola and Une chambre en ville), the echoes of Nantes are evident in the other cities of his works. Demy's vision of an enchanted universe was that of a utopian city full of colour and music, and at the same time a tribute to Hollywood musicals. The city is a dream place full of colours that help the development of the history and the characters; an essential element of the filmography of this author who becomes a character itself.

Keywords: Jacques Demy, utopian city, Nantes, ports, musical.

La filmografía del realizador francés Jacques Demy (1931-1990) se inscribe dentro de la eclosión cinematográfica de la Nouvelle Vague de los años sesenta. Un grupo de realizadores con objetivos comunes pero que sin duda toman caminos muy distintos. De entre todos ellos la figura de Jacques Demy, que ha quedado un tanto eclipsada a favor de directores mejor reconocidos (aunque hace un par de años se ha comenzado una recuperación), es la más innovadora, atrevida y rica. Una obra inusual y muy enriquecedora cuya fuerza descansa en la perfecta conjunción de lo pictórico, la música y los temas cotidianos. Jacques Demy a lo largo de toda su carrera ha creado un universo propio, acertada- mente definido por la productora Mag Bodard con la ocasión del estreno de Los paraguas de Cherburgo como "en-chanté", un mundo en el que los colores y la música arropan a unos personajes frecuentes que evolucionan película tras película con el trasfondo real de una Francia que Demy se empeña en reflejar en las ciudades de provincias. Con gran maestría técnica y artística nos sumerge en un universo personalísimo cerrado sobre sí mismo, cimentado sobre sus felices recuerdos de infancia y que sentará las bases para los futuros musicales europeos.

Al igual que sus compañeros cineastas de la Nouvelle Vague, sus historias se desarrollan en 
ciudades reales y perfectamente reconocibles. Pero la diferencia es que en contadas ocasiones situó sus historias en la capital francesa. Además hay que destacar que entre las filas del nuevo "grupo" cinematográfico la ciudad está cargada de un fuerte componente autobiográfico: la región de Creuse donde Claude Chabrol pasó la guerra se refleja en El bello Sergio (Le beau Serge, 1958) o su paso por la facultad de derecho de la Sorbona en Los primos (Les cousins, 1959); la ciudad de Ginebra de El soldadito (Le petit soldat, 1960) de Jean-Luc Godard o el París de la infancia de François Truffaut en Los cuatrocientos golpes (Les quatre cents coups, 1959). Jacques Demy nos presenta su ciudad ideal, siempre a partir de su deseo de descubrirnos un cosmos repleto de color y música homenajeando a los grandes musicales de Hollywood. Los orígenes bretones del cineasta marcarán sus trabajos. Su referente será Nantes. Él había nacido en Pontchâteau pero pasa toda su infancia y adolescencia en Nantes, la que considera su ciudad natal, su más directa inspiración urbana. Se debe señalar que también refleja su admiración por París, ciudad a la que va ya de adolescente para continuar sus estudios en el IDEH'. Este amor por Nantes que se observa en cada uno de sus trabajos. En realidad solo rodó en dos ocasiones en esta ciudad, sin embargo, sus ecos los ha trasvasado a las demás ciudades en las que se inscribe el resto de su obra. Así reconocemos los reflejos de Nantes en Niza, Cherbourg, Rochefort, SaintTropez, Marsella e incluso en Los Ángeles. Todas ciudades portuarias, en las que el mar cobra una relevancia más que significativa.

El director junto a su gran amigo y compañero, el decorador Bernard Evein, remodelan y transforman cada ciudad en un lugar de ensueño repleto de colores que complementan tanto el desarrollo de la historia como el carácter de los personajes. Siendo la ciudad un elemento indispensable y característico de la filmografía del autor que se convierte de este modo, en un personaje más.

Lola (1960), el primer largometraje de Jacques Demy, una de las obras emblemáticas de la Nouvelle Vague y el inicio de la construcción de todo el mundo único del director, transcurre en Nantes ${ }^{2}$.
Ya en esta primera película la idea del cineasta era elaborar una obra musical y polícroma pero el bajo presupuesto con el que contaba hizo imposible materializar este deseo. Aún así, este trabajo marca el inicio de lo pictórico, lo musical y la danza de obras posteriores; la excelente y precisa fotografía de Raoul Coutard no nos muestra solamente los colores blanco y negro, sino que hay toda una escala de grises que remarcan la identidad de los personajes. Y la célebre escena de Anouk Aimée cantando la canción de Lola (con letra firmada por Agnès Varda), junto con la perfecta combinación de la música de L. van Beethoven, J.S. Bach y W.A. Mozart, advierte todo lo que Jacques Demy quería contar.

Vemos un Nantes en blanco y negro, elegante y majestuoso, reflejo de la ciudad de infancia del cineasta marcada por los bombardeos de 1943.

El deseo de la evocación de su infancia feliz se vislumbra en cada rincón de la urbe que aparece en pantalla: Allée des Tanneurs donde se encontraba el taller de coches familiar y el desván en el que el pequeño Demy hacía sus primeros intentos cinematográficos; Cours SaintPierre, lugar en el que el que junto a los cines Katorza y Apollo y al Théâtre Graslin comenzó la temprana vocación cinéfila del director y su adoración por los guiñoles; el impresionante Passage Pommeraye en el que se compró su primera cámara y en dónde se situaba un cineclub al que asistía asiduamente...

Lola es un paseo autobiográfico por una ciudad luminosa de grandes espacios abiertos, en la que diferenciamos zonas que se corresponden a los personajes principales del film reafirmando su condición y su temperamento: el primero es el que se articula en torno al Quai de la Fosse y al puerto, es el que pertenece a Roland Cassard, en donde este se encontrará con su amor de juventud y en donde forjará su destino como diamantista (su habitación y su empleo, el café naval, el Café des Caboteurs, la place Royal y el Passage Pommeraye). El segundo espacio es el que domina Madame Desnoyers y su hija Cécile, se trata del centro urbano reconstruido tras los bombardeos durante la Segunda Guerra Mun$\mathrm{dial}^{3}$. La primera vez que vemos a estas mujeres es en la Place du Bon Pasteur, delante de la li- 
brairie Bellanguer y a pocos metros de Rue $d u$ Calvaire, cuya resurrección después de los bombardeos significó el renacimiento de la ciudad, y su apartamento se sitúa en Rue de Budapest, una calle que no se volvió a ocupar hasta 1952. La joven Cécile es la unión entre el mundo de Madame Desnoyers y la zona la de la protagonista ${ }^{4}$, así la niña sale de una escuela con una fachada del siglo XIX (que en realidad está situada en frente a lo que era el taller de coches de la familia Demy) acude a un kiosco en el Quai de la Fosse (librairie Coiffard que existe todavía) y arrastra a Frankie hasta la fiesta situada en Allée Turenne. El último sector de Nantes que se nos presenta es el que se ciñe a Lola, aunque se expone con menor claridad que los dos anteriores es un espacio que identificamos con el pasado barroco de la urbe que transcurre desde el exterior del apartamento en el que vive la protagonista situado en Rue de l'Abreuvoir (próximo a la Tour de Bretaña) hasta, sobre todo, la Place Graslin y "La Cigale", restaurante de estilo art noveau rebautizado como "El dorado" para el film, del que se muestra no la entrada principal con su fachada ornamentada sobre la Place Graslin sino la discreta entrada lateral por Rue Piron que no anuncia el estallido de decoración interior.

Pero Jacques Demy no es estrictamente fiel a la realidad de la ciudad. Lo que se nos muestra aquí es un Nantes remodelado a gusto del director, que inventa una imagen idílica de la que evita todo aquello que no le gusta o que no es necesario en la historia que desea contar. De este modo, cuando Lola lleva a su hijo a la escuela no hace un recorrido real, presenciamos una elipsis espacial pasando de Marchix a las antiguas calles de Île Feydeu (un lugar emblemático de la presencia artística del s. XVIII). O en el momento de la salida del colegio de Cécile, Frankie necesita atravesar una calle que en la realidad no se encuentra allí.

Con Una habitación en la ciudad (Une chambre en ville, 1982), una película completamente cantada y rebosante de color, Jacques Demy vuelve e filmar en su adorada Nantes (pero esta vez, a diferencia de en Lola, solamente rodará en la ciudad los exteriores recreando todos los interiores en estudios de París).
En esta ocasión Nantes se revela totalmente diferente con respecto al primer largometraje del cineasta. Sin duda el fuerte contraste del colorido empleado así como los diálogos totalmente cantados son las causas principales de esta diferenciación. Pero lo interesante, lo remarcable es que la ciudad que ahora se descubre ante el espectador cinematográfico es un espacio urbano cerrado, dispuesto como telón de fondo de la lucha de clases durante las cruenta huelga acaecida en la ciudad durante 19555: Enfrentamientos entre los astilleros navales y la policía que se enmarcan en la Rue du Roi-Albert flanqueada en un extremo por la prefectura de policía y al otro por la catedral. Es en esta calle en donde se sitúa también el amplio apartamento burgués de la coronela Madame Langlois (madre de la protagonista, Edith), el interior más relevante de todo el film 6 . Los demás exteriores se ubican en un perímetro bastante acotado que va desde la catedral hasta el Cours de St-Pierre y que se extiende hacia el oeste hasta la Place du Buffay y su mercado. También reconocemos la fachada del café obrero en una esquina entre la Rue Lanove-Bras-de-Fer y la Rue Sourdéac; no es reconocible en pantalla, pero la callejuela en la que se conocen Edith y Gilbaud es la Rue Régnard, justo detrás del restaurante "La Cigala", a pocos metros de la Rue Piron y la entrada del restaurante rodada en Lola.

Demy quiso filmar los astilleros pero no obtuvo la autorización necesaria y el puente transbordador que vemos al inicio de la película sobre el puerto, es posible gracias al glass-shot llevado a cabo por André Guérin que permite resucitar el puente desaparecido en los años cincuenta, un elemento urbano decisivo en la filmografía del cineasta e imagen indisociable a la silueta del puerto de Nantes que cruzaba de una orilla a otra del Loira.

Pero el lugar por excelencia de Nantes es el Passage Pommeraye, una galería cubierta que nada tiene que envidiar a las famosas galerías parisinas, construido en el s. XIX en el corazón de la ciudad con una ecléctica decoración realizada en madera, hierro y estuco. Al igual que en Lola, esta majestuosa galería tiene un lugar predominante en Una habitación en la ciudad, un emplazamiento idóneo que simboliza este 
mundo cerrado del cineasta en el que el azar dicta sus leyes, pero en dos versiones muy diferentes. Mientras que en la primera película se muestra como un espacio diurno, bullicioso que representa la elegancia y el lujo con una luz diáfana que se introduce por el techo de vidrio y se refleja en los innumerables espejos, el lugar en el que se reencuentran Lola y Roland y en el que este último comienza su beneficioso futuro con el contrabando de diamantes; en Una habitación de la ciudad aparece como una zona nocturna, desierta, inquietante y sórdida por la que Edith se pasea desnuda bajo su abrigo de visón y en la que el marido posesivo y celoso de ésta (Edmond) regenta una tienda de televisores en la que acaba suicidándose. Este contraste de Día/Noche es la constante y la base diferenciadora entre las dos películas, el ambiente "frívolo" de la primera y la atmósfera agobiante y militar de la segunda.

Sin embargo, algo común entre estos dos trabajos es el total rechazo de Jacques Demy en dar una visión turística, no hay ninguna visión del Castillo de los Duques de Bretaña o de la Catedral como monumentos (ésta aparece como punto de concentración y símbolo de fervor popular opuesto a la prefectura). Y de los soberbios palacetes del Quai de la Fosse y la Île de Feydeau, la cámara solo nos revela la planta baja debilitada por el paso del tiempo sin dejar rastro alguno de la decoración de sus fachadas. Si bien podemos entender la visión de "La Cigala" y el Passage Pommeraye como únicas excepciones de esta visión turística de la ciudad.

Bernard Evein apenas retoca los exteriores, quizás en la primera ocasión por falta de presupuesto y en la segunda porque todo esa abundancia de color característica en el cine de Demy se reserva para los interiores que contrastan con el frio azul de la piedra nantesa que arropa los cruentos enfrentamientos del film.

Jacques Demy soñaba con volver a rodar en Nantes, de hecho el último proyecto en que estaba trabajando antes de morir, Cobby, anhelaba poder llevarlo a cabo en esta localidad. Y aunque en realidad únicamente desarrollo dos de sus trabajos en su ciudad natal, esta estuvo siempre presente en su imaginario de lo que para él es una ciudad ideal. A lo largo de toda su filmografía con fuertes rasgos autobiográficos hay constantes aspectos que nos remiten una y otra vez a Nantes, la "ciudad-madre" del universo demyniano: ciudades de provincias portuarias de la costa oeste francesa, cuya presencia del mar es inagotable bajo diferentes aspectos (un mar que en Nantes se puede adivinar a través del Quai de la Fosse), los puentes transbordadores (ha rodado en tres de las cinco ciudades francesas que contaban con un puente transbordador), los pequeños comercios que dan vida a la ciudad, los marineros de paso...

El siguiente largometraje que hace Demy en blanco y negro y en el que cuenta con un muy reducido presupuesto es La baie des anges (1962), una historia que cuenta la destructora pasión de Jackie Demestre (una soberbia Jeanne Moreau que quiso trabajar con Jacques Demy desde que descubrió Lola) por el juego en los casinos de la costa azul francesa. En esta ocasión los lugares elegidos por el cineasta son París, Niza y MonteCarlo.

París representa la vida sencilla, tranquila y ordenada de Jean Fournier (primera interpretación de Claude Mann) que se adentrará cada vez más en el infierno del peligroso mundo del juego representado en Niza y Monte-Carlo, los principales escenarios del film.

La película se inicia con una abertura de iris sobre el rostro de una elegante Jacquie seguido de un espléndido y vertiginoso travelling hacia atrás que nos muestra todo el paseo marítimo de Niza, la llamada Promenade des Anglais. De nuevo el mar, pero esta vez se cambia la playa de La Baule a la que llegaba Michel en su descapotable blanco en Lola, por el mar mediterráneo que baña el lujoso paseo de Niza.

En este nuevo trabajo del director, tanto los exteriores como los interiores son reales. Así, el Hôtel des Mimosas es en realidad un viejo hotel medio abandonado situado en el centro de la ciudad. Se pueden diferenciar en esta obra dos categorías espaciales que se corresponden con los protagonistas: París y las estrechas y sinuosas calles de Niza se asocian a Jean Fournier quien poco a poco va adentrándose en la zona que domina Jacquie Demestre: los lugares donde reside el lujo, tanto en Niza como en Monte-Carlo, bañados por el cálido sol de la costa azul y por el infinito mar que tanto gusta a la protagonista. 
Las grandes panorámicas que ofrece Demy de estas dos ciudades francesas que encarnan la riqueza y el glamour por excelencia no tienen la intención de mostrarnos un destino vacacional ideal, sino todo lo contrario, el lujo y el dinero como exhibición del infierno en el que vive Jacquie y al que arrastra sin remedio a Jean, viviendo los dos una pasión devoradora de la que es casi imposible salir.

Niza como Nantes tiene una arraigada tradición portuaria. A lo largo de la Promenade des Anglais vemos como aparece en pantalla otro de los iconos por excelencia de Jacques Demy: parejas de marineros vestidos de blanco paseando por la ciudad? ${ }^{7}$. Y el mar presente en la ciudad desde el principio hasta el fin (el principio ya se ha comentado, paseos por la playa, el mar de Monte-Carlo se ve en todo su esplendor desde la terraza de suite alquilada por los protagonistas y la película acaba con un abrazo de la pareja que sale del casino de Niza situado frente al mar) en la ciudad aparece como símbolo de tranquilidad, eternidad pero también como el deseo y el medio a escapar de esa jaula con barrotes de oro en la que está prisionera Jacquie.

Es con Los paraguas de Cherburgo (Les parapluies de Cherbourg, 1964) cuando el cineasta cumple su sueño de hacer una obra totalmente "en-chantée", rebosante de color y con diálogos enteramente cantados. Obra por la que más se recuerda a Jacques Demy ganadora de la Palma de Oro en el Festival de Cannes de 1964, ese mismo año nominada a mejor película de habla no inglesa en los Oscar y film que dio a conocer a Catherine Deneuve (musa del cineasta). Este trabajo es el precedente directo de Una habitación en la ciudad, en el que se cuenta la historia de amor entre dos jóvenes de diferente clase social, Guy y Genèvieve, truncado por la guerra de Argelia.

La ciudad de Cherburgo gusta al cineasta desde el primer momento por su ubicación geográfica: una ciudad portuaria de la baja Normandía francesa cuya historia está muy ligada a la prosperidad traída por su puerto. En un principio se había pensado situar la historia en el Havre, pero finalmente Demy optó por esta ciudad que ya estaba ligada a su filmografía desde Lola. Es a Cherbourg donde Madame Desnoyers y Cécile se trasladan desde Nantes para comenzar una nueva vida al lado del padre de la pequeña; esta unión se reforzará cuando Geneviève nos hable de su amiga Cécile y la use como excusa para poder ir al teatro con su enamorado Guy. Nantes surge de nuevo en pantalla bajo bellas imágenes en blanco y negro del Passage Pommeraye cuando también vuelva a aparecer el personaje de Roland Cassard, quien ansía casarse con Geneviève, y cuente su historia de amor por Lola.

El rodaje tiene lugar durante ocho semanas, de agosto a octubre de 1963, enteramente en la ciudad de Cherbourg. Una ciudad real de nuevo abierta hacia el mar, pero plenamente idealizada por el director quien junto a su fiel decorador Bernard Evein aúnan en una sola calle todas las tiendas que aparecen en el film, repintando fachadas con múltiples colores y colmando interiores y vestuarios de estampados coloridos que son fiel reflejo de los caracteres de los personajes. Demy, Evein y Legrand crean la ciudad perfecta rebosante de tonalidades y armonías, fórmula que años más tarde repetirá en Nantes (con Una habitación en la ciudad como se ha explicado anteriormente) pero en esta ocasión usando la música de Michel Colombier. El color invade las calles de la ciudad, nada se deja al azar, ningún color anula a otro. Los contrastes tonales iluminan la ciudad y dan fuerza a la historia. Gamas de verdes, rosas, azules, rojos, amarillos aparecen ante nosotros como si se tratase de un cuadro de Kandinsky en pleno movimiento. El sueño se hace realidad, hay una perfecta conjugación de pintura, música e imagen cinematográfica. Nos adentramos en una atmósfera irreal articulada ante una base perfectamente real y reconocible: la ciudad.

La zona de la ciudad predominante en el film es el puerto con su puente transbordador. Los paraguas de Cherburgo comienza con una abertura de iris que da paso a una panorámica sobre el amanecer en el puerto. Esta nos lleva a un movimiento de cámara hacia el pavimento del suelo mientras que aparecen los títulos de crédito que desembocan en un desfile de figuras que en realidad no es otra cosa que un resumen de la historia que está a punto de comenzar: bajo la lluvia, escuchando el leitmotiv musical creado por Michel Legrand, atraviesan la pantalla bici- 
cletas, marineros, mujeres, parejas de enamorados... todos cubiertos de paraguas de múltiples colores que dejan paso a un cochecito de bebé hasta que el desfile se cierra con una hilera de 6 personajes bajo paraguas negros que presagian el mal final del relato volviendo a ascender la cámara para de nuevo ver un plano genera del puerto.

El puerto es el área desatacada de la ciudad un lugar de partidas y esperas para Demy, es este el sitio en el que pasean los enamorados planeando su futuro común y será también testigo de la infidelidad de Geneviève en su paseo con Roland para decirle que acepta vivir una vida más cómoda con él. Dos paseos, dos parejas y dos formas de presentarnos el mismo espacio: mientras que la marcha de Guy y Genèvieve tras su velada en el teatro ocurre por la noche repleta de alegría y con un aire de ensoñación amorosa propia del primer amor a modo de ilustración de la canción de Georges Brassens "Ils se tiennenet par la main/Parlent du lendemain/ Du papier bleu d'azur/Que revêtiron les murs/De leur chambre à coucher/lls se voient dèjà, doucement/Elle cousant, lui fumant/Dans un bien-être sûr/Et choisissent les prénoms de leur premier bébé"s, el segundo recorrido por el puerto, esta vez hecho por Geneviève y Roland, es a plena luz del día como si se quisiera señalar la traición de esta. Además será en un bar del puerto en donde Guy, a su llegada de Argelia, se refugie en los brazos de una prostituta irónicamente llamada también Geneviève.

Rochefort será la ciudad elegida por Jacques Demy para su siguiente película, Las señoritas de Rochefort (Les demoiselles de Rochefort, 1966) la historia de las gemelas Garnier que buscan el amor y desean tener éxito como compositora y bailarina en París. Un auténtico homenaje al musical americano (en el que ahora introduce verdaderos números de baile y canto) con las hermanas Françoise Dorleac y Catherine Deneuve al frente de un reparto constituido por actores emblemáticos del género como Gene Kelly, Georges Chakiris o Grover Dale que bailan coreografías de Norman Maen.

A Jacques Demy de Rochefort le sedujo sobre todo su estructura geométrica con su gran plaza central idónea para desarrollar los grandes ballets y su puente transbordador que atravesaba el rio Charente. Es la ciudad utópica que buscaba para una historia en la que los personajes se desplazan bailando ante fachadas repintadas de colores pastel. Demy y Evein vuelven a dar una nueva cara a la urbe pintando $40.000 \mathrm{~m} 2$ de fachadas, transformando tiendas y creando el acristalado bar de Yvonne en plena plaza Colbert, punto neurálgico del film. La transición de la realidad a esta realidad imaginaria de Demy sucede al inicio de la película, con la escena de la llegada de los feriantes a Rochefort bailando sobre el puente transbordador 9 .

La primera imagen de Rochefort que nos ofrece el cineasta es la de una villa a la que se accede a través de su adorado puente transbordador, figura predominante en su infancia nantesa. Un emplazamiento fortificado y bien resguardado (lo primero que vemos es el cuartel militar) en la que el mar está presente siempre simbólicamente a través de las figuras de los marineros, de los barcos de juguete que navegan por la fuente central de la place Colbert y de todas las ciudades que se nombran a lo largo del film. ${ }^{10}$

Además de los elementos y figuras recurrentes que nos llevan hacia la ciudad natal del director, la filiación va más allá. El personaje de Maxence, un marinero de permiso interpretado por Jacques Perrin, aprovecha sus días de permiso para ir a ver a su familia a Nantes. Por otro lado los dos feriantes Bill y Etienne interpretados por los americanos Chakiris y Dale se conocieron en Cherburgo.

Lo que Demy nos ofrece es una transfiguración de la realidad a base de color, melodías y danza, en la que el despacho del alcalde se repinta de rosa para ser el apartamento de las gemelas, un almacén de comida se convierte en la fachada de la escuela en la que estudia Bou-Bou, la tienda de música de Monsieur Dame se sitúa en una esquina de la lonja o la Rue de la Republique pasa a ser en un juego irónico la Rue de la Bienséance (en español el nombre se traduce por buenos modales, urbanidad) donde Doutrouz asesina a la bailarina Lola-Lola (un nuevo guiño del director al que fuera su primer largometraje)...

Rochefort-sur-Mer será conocida a partir de 1967 gracias a Jacques Demy. El hecho del ro- 
daje se convierte en un fin turístico en sí mismo, explotado para resaltar esta localidad francesa sobre todo a partir del homenaje que Agnès Varda, viuda del cineasta, realiza con Les demoiselles ont eu 25 ans (1993). Un documental en el que se evidencia el rodaje feliz de Las señoritas de Rochefort así como la fiesta celebrada en la ciudad el 5 de junio de 1992 con ocasión del 25 aniversario del rodaje del film, momento en el que a los desaparecidos Jacques Demy y Françoise Dorleac se les recuerda consagrando una avenida y una plaza con su nombre.

La importancia de Niza, Cherburgo y Rochefort está implícita en el propio título de cada film, concediéndole una importancia capital antes de ni siquiera comenzar a ver las películas ${ }^{11}$.

Con Estudio de Modelos (Model Shop, 1968) viajamos de la costa noroeste de Francia a la costa californiana, a Los Ángeles. Por fin se cumple el sueño americano del director, ofreciéndosenos un sincero relato testigo de la época, de la contracultura americana y el rechazo ante la guerra de Vietnam a través de la continuación de la historia de Lola. Ahora abandonada por Michel, quien la ha dejado para sucumbir ante los encantos de Jaquie Demestre y el frenesí del juego, trabaja como modelo en lo que será un precedente del peepshows para poder juntar el dinero suficiente y regresar a Nantes junto a su hijo. Lola encuentra a Georges, un joven americano, o mejor dicho es él quien la encuentra a ella, y a través de estos personajes descubrimos una ciudad sin ningún tipo de fantasía añadida. Una especie de road-movie que explora el oeste de Los Ángeles de forma casi documental, de Venice a Hollywood pasando por Beverly Hills presentando un fidedigno testimonio de la sociedad de la época como casi nadie ha mostrado en el cine.

Los interiores relevantes como el estudio de modelos se han reconstruido en estudio, a excepción de los lugares de paso que forman parte de la ciudad: la casa del grupo de rock "The Spirit", la tienda de fotografías, la sala de billar, las oficinas del banco o el bungaló en el que viven George y Gloria. Es el estudio de modelos en el que trabaja Lola en donde vemos un desbordante uso del color (rosa) tan frecuente en la filmografía del cineasta; un lugar separado del mundo real al que se accede mediante estrechos y oscuros pasillos.

De nuevo el film comienza con una apertura de iris sobre un terreno en construcción con la playa al fondo. Esta vez la unión con Nantes a través del mar se hace por medio de la continuación historia de Lola cumpliéndose el anhelado deseo del director de trabajar en América y contando con unas facilidades de rodaje de las que hasta ahora no había dispuesto. Unas condiciones perfectas sobre el reflejo de su idílica ciudad; una lástima que el film tuviese una mala acogida esperándose de Jacques Demy un trabajo más en la línea de Los paraguas de Cherburgo.

El siguiente escenario, La Treille Muscate en Saint Tropez, le viene "impuesto" al director, ya que se trata de la adaptación de la novela de Colette La naissance du jour. La propia hija de la novelista, Colette de Juvenel, insistió al cineasta para que convirtiese esta historia en un filme para la televisión en 1980.

El rodaje de la narración autobiográfica de Colette tiene lugar en la propia casa de la escritora, en el escenario de la novela. Una historia con la que Demy se siente cómodo y le resulta fácil identificarse, la relación madre -hija tan frecuente en su filmografía está aquí, muy presente a través de Colette y su madre Sido, la fidelidad, la reflexión sobre uno mismo y el mar... Como es habitual el film comienza y finaliza con un iris sobre la playa de Saint Tropez, esta vez Colette (admirablemente interpretada por Danièle Delorme quien ya había realizado el papel de Gigi, una de las obras más famosas de Colette) abre la película paseando por la playa de camino a la Treille Muscate bajo el sol de la mañana y finaliza la película saliendo de casa hacia un mar bañado por una hermosa luz de la puesta de sol.

Demy hace suyo el escenario propio de la escritora no sólo en su compartido amor por el lugar de la acción sino también en los interiores donde observamos los mismos papeles pintados utilizados ya en Los paraguas de Cherburgo.

El último trabajo del director será Trois places pour le 26 (1988), una película en la que llevaba muchos años trabajando y en la que por fin cuenta con su admirado Yves Montand. La historia cuenta la vida de Yves Montand, quien 
se interpreta a sí mismo, un actor de fama mundial que vuelve a Marsella para representar en la ópera un musical sobre su vida. Jacques Demy nos presenta aquí un trabajo que sigue las convenciones más antiguas del género: un backstage musical. Un desfile de números musicales a través de la vida de Montand que se entremezcla con la historia que sucede cuando regresa a Marsella. Esta ciudad es la opción perfecta ya que es en donde creció Yves Montand y para Demy es, al igual que Nantes, un próspero puerto de comercio que también cuenta con un puente transbordador además de ser la ciudad de provincias francesa que tiene un imaginario cinematográfico más extenso.

Los exteriores se ruedan enteramente en el núcleo urbano mientras que los interiores son reconstruidos en los estudios SFP en Bry-surMarne, con excepción de la escena de la librería y la escena de la Ópera con público. Reconocemos Marsella sobre todo por las escenas de las escaleras de la station Saint Charles y, aunque nunca llegamos a ver el puente transbordador, este está presente los números musicales que cuentan la historia de Montand, formando parte indispensable del decorado. Porque el puente transbordador es símbolo de la infancia del artista y del director junto a los marineros, el mar, la música...

Nunca estuvo tan justificado el título de una película como en el caso del homenaje que Agnès Varda hace al que fuera su marido. Jacquot de Nantes (1991) es una carta de amor, un testimonio de la vocación y evocación que nació en

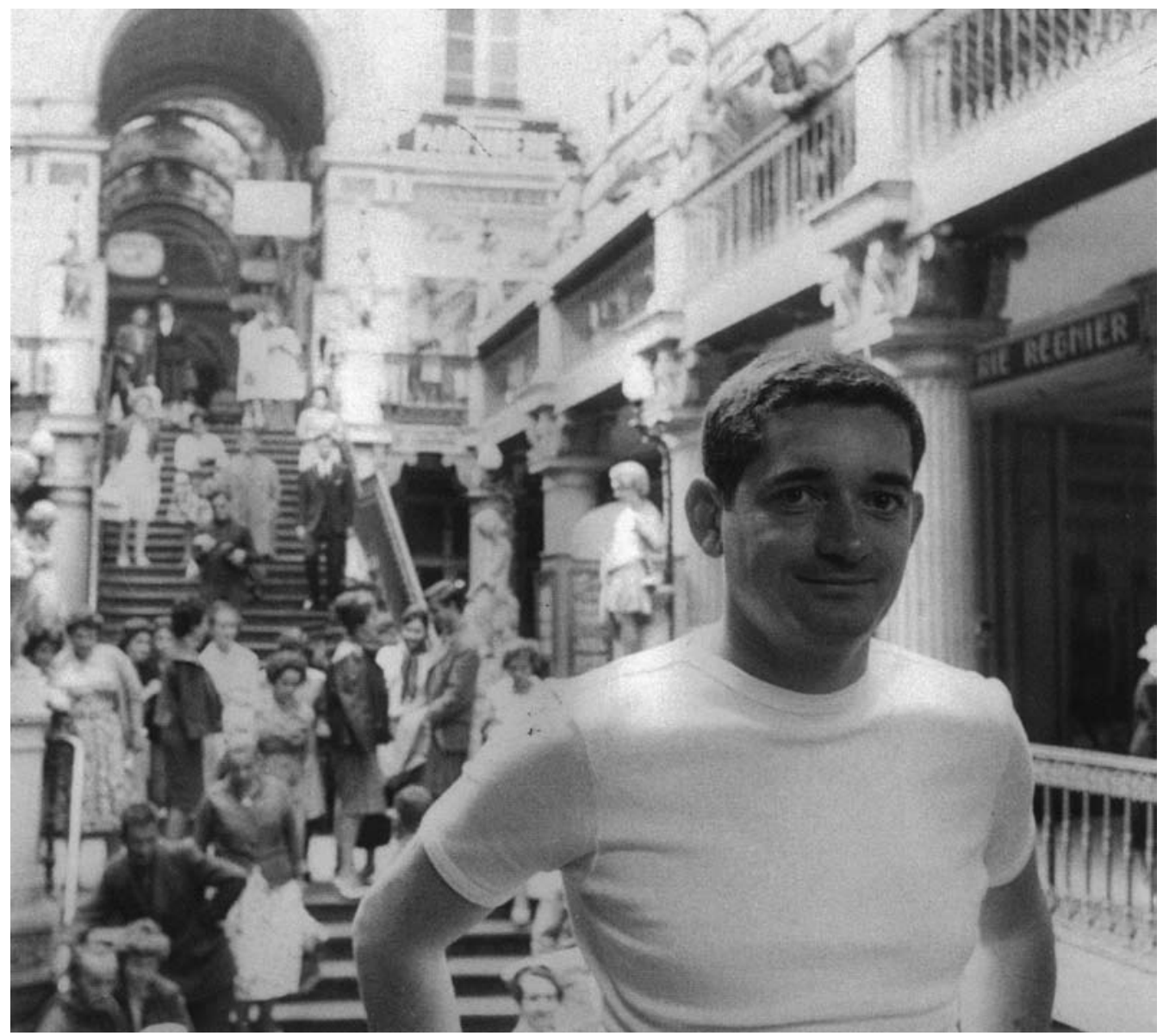

Fotografía de Agnès Varda durante el rodaje de Lola (1960). Cortesía de Ciné-Tamaris 
el pequeño Demy en la ciudad de Nantes. Todo el relato está construido a partir de los recuerdos que el cineasta escribe y da a su mujer, quien los lleva a la pantalla con una fuerza y una dulzura extraordinaria. Es el relato del aprendizaje de un maestro, su sensibilidad y amor por el cine que se articula en torno a tres ejes narrativos (el relato de infancia, la vocación de un futuro cineasta y el retrato de Jacques Demy poco antes de su muerte) presentando diez años claves en la vida del director en los que se muestran las referencias de su futura filmografía: las canciones, las películas y los espectáculos que hicieron al niño tomar el camino elegido.

De hecho, este film lo comenzó Varda cuando la enfermedad de Demy estaba ya demasiado avanzada como para que él mismo trasladase a la pantalla sus recuerdos. El rodaje comenzó en Nantes en 1990 pero se finalizaría en París cuando el cineasta estaba ya muy enfermo. Jacques Demy muere diez días después de acabar el rodaje, pero Varda sigue adelante con el montaje del film, que es la mejor y más fiel muestra de admiración posible. La película muestra de manera muy clara cómo los lugares de Nantes han influido en la filmografía del director. Tras contemplar la ciudad de 1938/39 vemos de qué manera estos lugares emblemáticos pasan bajo el tamiz de la mirada ya innovadora y colorista del pequeño Jacquot.

Hay cineastas que son verdaderos urbanistas, arquitectos que juegan con el espacio urbano ofreciéndonos sin reservas un acceso privilegiado en el que se mezclan lo real y la visión personal de cada autor. Jacques Demy ha dado a Nantes una paleta de sentimientos y de emocio- nes que dan forma y crean la identidad propia de la ciudad. Y esta le ha correspondido otorgándole un lugar privilegiado en su historia. Hoy en día existe un recorrido turístico, "Une balade avec Jacques Demy"12, por los lugares cinematográficos de Jacques Demy. Además la mediateca de Nantes lleva el nombre del director y en 2010 se ha realizado una gran exposición en torno a la figura del cineasta contando con proyecciones, conferencias, conciertos, etc. Ilamada "Un nantais nommé Jacques Demy" ${ }^{13}$.

El espíritu de la ciudad acompaña a Jacques Demy a lo largo de toda su carrera cinematográfica y por ende está presente siempre en su vida personal, es la verdadera inspiración del artista. Julien Grac diría de Nantes "que ella me acompañe, pues, como uno de esos vademécums que se pasean por todas partes, que se anotan y se rayan sin miramientos, agenda que se consulta siempre de manera cotidiana e inconsciente, a la vez trampolín inutilizables, que ha hecho que se ahondaran y endurecieran en mí los pasos que me imponía"14, una reflexión idónea para el caso Demy. (Imagen 1)

Después de descubrir los trabajos de Jacques Demy, Nantes nunca volverá a ser la misma. Madre de Niza, Cherburgo, Rochefort, Los Ángeles, Saint Tropez y Marsella nos descubre una vida diferente a la de la capital, un pequeño universo autónomo que se revela ante nosotros como un cuento (el uso del iris refuerza esta idea) lleno de color y música pero también un mundo anclado en la realidad no tan naïf como pueda parecer a primera vista, que nos invita a conocer la vida cotidiana de los pequeños comercios de las ciudades portuarias francesas. 


\section{NOTAS}

${ }^{1}$ La visión que ofrece de París es muy concreta. No es una visión turística sino que lo que nos ofrece el director es la parte de la ciudad que se corresponde con su vida y sus gustos. Su cortometraje La luxure dentro del film común Les Sept péchés capitaux (1961) que cuenta la historia de dos antiguos amigos, Jacques y Bernard(como el director y el decorador) que se reencuentran y recuerdan en una cafetería de París su confusión infantil entre lujuria y lujo. No te puedes ni fiar de la cigüeña (L'evénement le plus important después que I'homme a marché sur la lune, 1973) se desarrolla enteramente en el barrio de Montparnasse en el que habitaba Jacques Demy, en la Avenue du Maine y la Rue de la Gaîté. La adaptación del comic La rosa de Versalles, Lady Oscar (1978), que centra la historia en la joven Oscar que haciéndose pasar por hombre es guardia personal de la reina María Antonieta hasta que estalla la Revolución francesa, es una producción ambiciosa en la que sin embargo hubo que recrear la toma de la Bastilla en los exteriores de Senlis. Parking (1982) su siguiente trabajo en París, en el que se cuenta una renovada visión del mito de Orfeo, en la que este es un famoso cantante pop, sucede sobre todo en los alrededores del palacio de congresos de Bercy.

Hay que dejar a un lado las dos adaptaciones de cuentos infantiles que realizó el director: Piel de Asno (Peau d'âne, 1970) y El flautista (The pied piper, 1971) en los que los que los emplazamientos se sitúan en Gambais y los castillos de Chambord y PlessisBourre en el primero, y Alemania en el segundo.

${ }^{2}$ La ciudad de Nantes tiene orígenes galos, fue la capital de Bretaña (s. $\mathrm{XI}-\mathrm{XV}$ ) y ahora es la capital de la región de Pays de la Loire, situada en el Loira
Atlántico y con una fuerte y arraigada historia industrial portuaria.

${ }^{3}$ La ciudad está íntimamente unida al entorno social, sus diferentes condiciones físicas determinan la relación con el contexto humano. Con la evolución del cine seguimos los cambios del núcleo urbano, así cine y ciudad van de la mano en su desarrollo. Stephen Barber plasma perfectamente esta idea: "Las imágenes de las ciudades europeas registradas por el cine, iluminan el pasado y el futuro de la morfología urbana, la crisis y las sensaciones de sus habitantes se proyectan a través de la infinita capacidad del cine europeo para yuxtaponer las identidades humana y urbana dentro de una relación opuesta que puede resultar brillante o consecuentemente, según los caprichos o las convicciones humanas y tecnológicas de cada director". Barber, Stephen: Ciudades proyectadas. Cine y espacio urbano. Ed: Gustavo Gili S.L.Barcelona, 2006. Pág. 5.

Queda patente el cambio en la fisonomía de Nantes tras los bombardeos de 1943 y las modificacios en el Erdre a principios del siglo XX

${ }^{4}$ Es lógico que Cécile simbolice la unión entre los dos espacios de Madame Desnoyers y Lola, ya que esos tres personajes son en realidad la misma persona. Son la representación de las tres edades de Lola (el pasado reflejado en Cécile, que es el verdadero nombre de Lola; el presente expresado como una bailarina de cabaret y el posible futuro revelado por Madame Desnoyers que vive sola junto a su hija).

${ }^{5}$ Jacques Demy cuenta la historia de amor entre Edith, joven perteneciente a una burguesía venida a menos, y Gilbaud un obrero de la metalurgia en el momento de una de las huelgas más cruentas de Francia en 1955. Un nuevo referente biográfico del director, además de basarse de igual modo en la huelga también ocurrida en Nantes en 1922 y vivida por su padre. Un hecho histórico en el que se basa el film remarcando su realidad gracias al inicio en blanco y negro.

${ }^{6}$ Realmente se alquila un apartamento en el primer piso del número 9 de la Rue Roi-Albert para que la primera vez que veamos a Danielle Darrieux (Madame Langlois) asomada en la ventana, observando los enfrentamientos entre policías y obreros, este realmente allí. Así como la entrada al edificio que también es auténtica. Pero el amplio interior como todos los demás interiores y como se ha indicado ya antes está construido en un estudio parisino.

7 Herederos directos de los protagonistas de Un día en Nueva York (On the Town, 1949. Stanley Donene y Gene Kelly)

8 "Ellos se cogen de la mano/ Hablan del mañana/Del papel azull Con el que cubrirán las paredes/De su habitación/Se ven ya dulcemente/Ella cosiendo, el fumando/En un bien estar seguro/Y eligen los nombres de su primer bebé". Canción Les amoreux des bancs publics de George Brassens

${ }^{9}$ Puente que Bernard Evein quería repintar totalmente de color rosa, pero era demasiado costoso y además no se obtuvo el permiso necesario por parte de las instituciones

10 Todas las ciudades que se nombran, excepto París, tienen mar: Nantes, Hambourg, Acapulco, Venise, Manille, Lima y las islas de Java, Bali, Marquises y Sein.

${ }^{11}$ Niza es conocida por los franceses como La baie des anges (La bahía de los ángeles).

12 "Un paseo con Jacques Demy".

13 "Un nantés llamado Jacques Demy"

${ }^{14}$ Gracq, Julien: La forma de una ciudad. Anabasis. Madrid, 1995. Pág. 11 